\title{
ARQUEOLOGÍA Y CINE: DISTORSIONES DE UNA CIENCIA Y UNA PROFESIÓN
}

\author{
Archaeology and cinema: distorsions of a science and a profession \\ Carlos Tejerizo García \\ Becario FPU de la Universidad del País Vasco/ \\ Euskal Herriko Unibertsitatea \\ E-mail: carlosteje@gmail.com
}

Fecha de recepción: 6-III-2011

Fecha de aceptación: 13-III-2011

Resumen: Sólo en los últimos años la investigación arqueológica se ha dirigido a analizar la relación de esta ciencia con el contexto social, político o económico actual. La grave distorsión que existe entre la imagen de la Arqueología de los profesionales y la imagen social es tratada a través de una treintena de películas analizando, igualmente, las consecuencias que en el mundo académico, educativo y profesional tienen este tipo de distorsiones. Finalmente, se propone una Arqueología "militante" basada en algunos postulados de la Teoría Crítica y el materialismo dialéctico como solución a este distanciamiento entre la Arqueología y la sociedad.

Palabras clave: Arqueología; cine; medios de comunicación de masas; opinión pública; arqueología profesional; Teoría Crítica; materialismo dialéctico.

ABSTRACT: Only in recent times the archaeological research has focused on the relationship between this science and the social, political and economical context. The serious distortion that exists between the professional image of Archaeology and the social one is analysed through thirty films, standing out the consequences that this distortion has in the academic, educative and professional areas. Finally, a militant Archaeology based in the postulates of the Critic Theory and the dialectic materialism is proposed as a solution of this division between Archaeology and society.

Key words: Archaeology; popular film; mass media, public opinion, professional archaeology; Critic Theory; dialectic materialism. 


\section{INTRODUCCIÓN ${ }^{1}$}

Tras más de 150 años, la Arqueología puede considerarse finalmente como una ciencia madura en términos de metodología, objeto de estudio y reconocimiento académico ${ }^{2}$. Sin embargo, este desarrollo científico de la disciplina no ha venido siempre acompañado de una reflexión metacientífica que analizase su relación con la sociedad en la que se inserta. Únicamente desde finales de los años 80, de la mano de las corrientes posprocesuales, la investigación se ha dirigido hacia esta compleja relación Arqueologíasociedad-política-economía cuyo mayor éxito ha sido el de abrir nuevos campos de estudio lejos de lo académicamente "científico" 3 . En este sentido podrían destacarse el estudio de la relación del nacimiento de la Arqueología con los nacionalismos ${ }^{4}$, Arqueología y política ${ }^{5}$, Arqueología e ideología ${ }^{6}$ o Arqueología, educación y economía ${ }^{7}$, por citar sólo unos pocos ejemplos.

A pesar de estos recientes pasos, la Arqueología parece seguir desvinculada de la sociedad si observamos la distorsión entre lo que la Arqueología es y potencialmente puede ser (la imagen del profesional) y lo que la sociedad recibe y percibe de ella (la imagen de la sociedad). ${ }^{8}$. Mientras que los investigadores se han preocupado mucho por la primera de las imágenes, la segunda sigue siendo un territorio por explorar, y no por falta de análisis, sino por falta de una base crítica y una praxis social concreta?

\footnotetext{
1 Quería agradecer a Egoitz Alfaro, Aitor Calvo, Álvaro Carvajal, Marta Fernández, Idoia Grau, Clara Hernando, Aitor Sánchez e Itsaso Sopelana su ayuda en la búsqueda de películas y sus consejos para la redacción de este texto.
}

2 TRIGGER, B. (2009). A bistory of Archeological Thought. Cambridge: Cambridge University Press.

3 En este sentido, la influencia de Feyerabend en las teorías posprocesuales de la Arqueología es innegable; Ibid, FEYERABEND, P. K. (1975). Contra el método. Barcelona: Ariel.

4 DÍAZ-ANDREU, M., y CHAMPION, T. (1996). Nationalism and archaeology in Europe: an introduction. En M. DÍAZ-ANDREU \& T. CHAMPION (Eds.), Archaeology and Nationalism in Europe (pp. 1-23). Londres: UCL Press.

5 DÍAZ-ANDREU, M., y MORA, G. (1995). Arqueología y política: el desarrollo de la arqueología española en su contexto histórico. Trabajos de Prehistoria, 52(1), 25-38.

6 ACIÉN ALMANSA, M. P. (1994). Política y Arqueología ¿dependencia? Arqueología y Territorio Medieval(1), 67-74.

7 RUIZ ZAPATERO, G. (2009). ¿Qué arqueología enseñar en la universidad del siglo XXI? Complutum, 20(2), 225-254, PARGA-DANS (2010). Commercial archaeology in Spain: its growth, development, and the impact of the global economic crisis. En N. SCHLANGER \& K. AITCHISON (Eds.), Archaeology and the global economic crisis. Multiple impacts, possible solutions (pp. 45-54). Tervuren: Culture Lab Editions.

8 ALMANSA SÁNCHEZ, J. (2006). La imagen popular de la Arqueología en madrid. Arqueoweb: revista sobre Arqueología en Internet, 8(1).

9 HORKHEIMER, M. (2003 [publicado en 1937]). Teoría tradicional y teoría crítica. En 
Sin negar las numerosas propuestas de acercamiento real y efectivo de la Arqueología a la sociedad ${ }^{10}$, esa distorsión sigue existiendo.

Este problema, lejos de carecer de importancia, tiene una incidencia sobre aspectos de la realidad cotidiana de la Arqueología a través de la aplicación de las políticas públicas. La cuestión de la relación entre opinión pública y políticas públicas, es decir, la relación entre lo que la sociedad quiere que realicen las administraciones y lo que éstas efectivamente llevan a cabo es un tema muy estudiado dentro de la politología y la filosofía ${ }^{11}$, lo que nos llevó en su momento a afirmar que realmente la visión social de la Arqueología afecta directamente a su estatus y condición tanto en lo científico como en lo social ${ }^{12}$.

El cine es un buen instrumento de análisis de esta problemática ya que constituye uno de los medios más importantes por los que la sociedad (española) recibe la información sobre lo que hace la Arqueología; sólo en el año 2009, los cines del Estado recibieron 110 millones de espectadores ${ }^{13}$. Sin embargo, hay que tener en cuenta que la industria del cine, como toda empresa, persigue un beneficio, por lo que los estereotipos fílmicos suelen estar influidos por otras variables como son las "necesidades del guión", la maximización de beneficios, etc. que hay que tener en cuenta a la hora de analizar las películas. Como afirma Mark Hall: "Even the most authentic of films can have their authenticity vitiated by the political context in which they are made by the costs of production (money and time), and by the need for a commercial or propaganda return"14.

Para la realización del presente trabajo hemos analizado un total de 30 películas ${ }^{15}$ analizando variables fijas en todas ellas, como las características

M. HORKHEIMER (Ed.), Teoría crítica (pp. 223-271). Madrid-Buenos Aires: Amorrortu Editores.

10 FALQUINA APARICIO, Á., MARÍN SUÁREZ, C., ROLLAND CALVO, J. y TIERRA DE NADIE, G. A. (2006). Arqueología y práctica política. Reflexión y acción en un mundo cambiante. Arqueoweb: revista sobre Arqueología en Internet, 8(1).

11 OLMEDA GÓMEZ, J. A. (2008). Las políticas públicas en la práctica. En J. A. OLMEDA GÓMEZ (Ed.), Ciencia de la Administración, volumen I: Teoría de la organización y gestión pública (pp. 539-586). Madrid: UNED, HABERMAS, J. (1981). Historia y crítica de la opinión pública. Barcelona: Gustavo Gili, D.L.

12 CARVAJAL, Á., HERNÁNDO, C., DE SOTO, R., y TEJERIZO, C. (en prensa). El síndrome de Indiana Jones: la imagen social del arqueólogo.

13 http://es.reuters.com/article/entertainmentNews/idESMAE60K00420100121 [consultado el 06/02/2011].

14 HALL, M. (2004). Romancing the stones: archaeology in popular cinema. European Journal of Archaeology, 7(2), 159-176.

15 Las películas consideradas en el artículo son: Lara Croft: Tomb Raider (2001); Muerte en el Nilo (1978); La Momia (1932); Jack Hunter y el tesoro perdido de Ugarit (2008, dividida 
del arqueólogo o arqueóloga, la visión transmitida de la disciplina, la metodología arqueológica seguida, etc. La elección de las películas respondió a criterios basados en la propuesta de Howard Day ${ }^{16}$, por lo que las películas debían:

1. Contar con la presencia de un arqueólogo o arqueóloga (o equivalentes, como los "aventureros").

2. Tener elementos arqueológicos como centro de alguna escena o escenas $^{17}$.

3. No ser una película documental o de divulgación científica, excluyendo para este estudio las series de televisión.

4. Ser producidas principalmente para el entretenimiento.

En el análisis de las películas no se busca únicamente describir la Arqueología o al arqueólogo o arqueóloga. Más allá de los planteamientos "narcisistas" que, según Ben Marwick ${ }^{18}$, estudian pasivamente la imagen de la Arqueología en el cine, el objetivo es analizar las consecuencias que esta imagen tiene en la realidad arqueológica para tratar de delinear algunas respuestas que podemos dar a esta problemática.

en tres partes); Stargate: puerta a las estrellas (1994); La Momia nacional (1981); La momia (1999); La momia 2. El regreso (2001); La momia 3. La tumba del emperador Dragón (2008); Blade 3: Trinity (2004); The relic (1997); El templo del oro (1986); Manhattan Baby (1982); The body (2001); Tomb Raider 2: la cuna de la vida (2003); Timeline (2003); La Rosa Púrpura del Cairo (1985); Westworld (almas de metal) (1973); Indiana Jones: en busca del arca perdida (1981); Indiana Jones y el templo maldito (1984); Doc Savage: man of bronze (1975); Indiana Jones y la última cruzada (1989); La búsqueda: el tesoro nacional (2004); A month in the country (1987); The mask of Fu Manchu (1932); Indiana Jones y el reino de la calavera de cristal (2008); Jurassic Park (1993); La búsqueda 2: el diario secreto (2007); El exorcista (1973); El quinto elemento (1997).

16 HOWARD DAY, D. (1997). A treasure hard to attain. Images of Archaeology in popular film, with a filmography. Londres: The scarecrow press.

17 MARWICK, B. (2010). Self-image, the long view and archaeological engagement with film: an animated case study. World Archaeology, 42(3), 394-404.

18 Ibid. 


\section{LA ARQUEOLOGÍA: UNA CIENCIA DISTORSIONADA}

\section{1. ¿Para qué sirve la Arqueología?}

Willie: creía que los arqueólogos eran unos graciosos hombrecillos que buscaban momias.

(Indiana Jones y el templo maldito, 1984)

Ladrón de tumbas: ¿Qué es esta porquería? ¿Qué demonios hacian esos egipcios? Acumular trastos y más trastos inútiles. Eso es lo que hacian. ¡Cuánta basura antigua!

(La momia 2: el regreso, 2001)

Henry Jones: la búsqueda del grial no es arqueología, es la lucha contra el mal. (Indiana Jones y la Última Cruzada, 1989)

Aunque el papel interpretado por Kate Capshaw en Indiana Jones y el templo maldito representa una mujer estereotipada y no el de una profesional, da en el clavo de lo que la Arqueología hace en el cine; buscar y encontrar, "search and retrieve"19. El objeto es el que da a la Arqueología su sentido y es su único fin. De hecho, normalmente se trata de objetos muy significativos dentro de la Historia del hombre; la caja de Pandora en Tomb Raider: la cuna de la vida; el Arca de la Alianza de Indiana Jones: en busca del arca perdida; la espada de Gengis Khan en La máscara de Fu Manchu o el libro de los muertos en La Momia. La figura del "objeto" también puede ser suplantada por un "colectivo de objetos singulares" que recibe el nombre de "tesoro". Con esto se transmite la idea de que la Arqueología busca objetos importantes y no cualquier "baratija" como cerámicas de época visigoda o huesos prehistóricos, que no recibe la atención de los arqueólogos. Esta idea puede verse en una escena de la película Jack. Hunter y el tesoro perdido de Ugarit, donde Albert Littman (el antagonista) recorre una excavación cogiendo algunas cerámicas (en perfecto estado), que, al considerarlas sin importancia, tira al suelo. En resumen, la recuperación del objetos singular se convierte en la propia razón de ser de la Arqueología sin la cual no tendría sentido; lo que vaya más allá de la búsqueda no tiene importancia.

El hecho de que las cerámicas recuperadas por Littman estuvieran enteras refuerza el hecho de que la Arqueología no sólo busca objetos, sino que éstos tienen que ser objetos "bonitos". En la Arqueología diaria, encontrar una cerámica completa es algo muy poco común. Normalmente los restos, estructuras o materiales excavados se encuentran de forma muy parcial, fragmentados o, incluso, ausentes (como ocurre con las estructuras construidas sobre postes); sin embargo, el espectador de cine recibe la imagen de unos arqueólogos que encuentran nada más ni nada menos que el santo Grial (Indiana Jones y la última cruzada) o la tumba intacta del emperador Qin con todos los soldados de terracota en ella (La Momia 3: la tumba del emperador dragón). La consecuencia es que, cuando éstos llegan a la Arqueología real, se decepcionan por los resultados reales.

19 HOWARD DAY, D. (1997). A treasure hard to attain. Images of Archaeology in popular film, with a filmography. Londres: The scarecrow press. p. 3. 
Este razonamiento nos lleva a otro problema; sólo las excavaciones que sacan a la luz restos "bonitos" suele ser digna de admiración y, en muchas ocasiones, de subvención económica, mientras que aquellas cuyos restos no son tan evidentes a la vista quedan en un segundo lugar. También los arqueólogos del cine se decepcionan; en La Momia (1932), cuando terminan las excavaciones sólo han podido hallar unos restos de cerámica, una momia y un cofre, lo que hace que el joven arqueólogo le diga a Sir Joseph: "Pues a mi me parece que ese cofre que hemos conseguido boy gracias a ese caballero tan extraño es el único descubrimiento que bemos hecho en dos meses que nos proporcionará una medalla del Museo Británico". La correspondencia en la Arqueología real es la costumbre muy extendida de "vender" las bondades de nuestras excavaciones tanto al público como a las administraciones, resaltando los aspectos más espectaculares, exclusivos o de corte más regionalista o nacionalista ${ }^{20}$ con el fin de conseguir el favor de unos y otros.

La importancia o valor de estos objetos es, por tanto inherente e inmanente; el valor del objeto se encuentra y acaba en él. En las películas los tesoros suelen tener dos valores diferentes; uno histórico/funcionalista (normalmente relacionada con hechos históricos muy concretos) y otro económico. Con "funcionalista" me refiero a la característica "esotérica" de muchos de los objetos de poseer poderes o cumplir una función determinada que los protagonistas o antagonistas quieren usar. En La Momia (1999) uno de los aventureros usamericanos, cuando descubren un libro egipcio grita indignado: "¿Un libro? ¿A quién le importa un libro? ¿Dónde coño está el tesoro?" El guía que sabe el valor "histórico/funcionalista" del libro (resucitar a los muertos) le responde: "esto, caballeros, es un tesoro -y, después de que se abre un compartimento secreto, dice- ahi está su tesoro" a lo que responde el aventurero; "ahora si que hemos encontrado algo". Es de destacar el uso del posesivo "su", que marca una apropiación privada y personalista de los objetos que luego comentaremos.

En esta búsqueda inmanente del objeto termina la labor de la Arqueología. La escena que mejor representa este hecho es la enigmática última escena de Indiana Jones: en busca del arca perdida cuando observamos cómo se llevan la mismísima Arca de la Alianza a un almacén con miles y miles de cajas similares, condenada al olvido para ser supuestamente estudiada por "nuestros... expertos" (top... men) de la CIA y el FBI. Este aspecto es también visible tanto en Jurassic Park como, más indirectamente, en Timeline, ambas basadas en novelas del recientemente fallecido Michael Crichton $^{21}$. En la primera, la "resurrección" de los dinosaurios (el objeto)

20 DÍAZ-ANDREU, M., y CHAMPION, T. (1996). Nationalism and archaeology in Europe: an introduction. En M. DÍAZ-ANDREU \& T. CHAMPION (Eds.), Archaeology and Nationalism in Europe (pp. 1-23). Londres: UCL Press.

21 Las películas basadas en novelas suelen estar bastante más documentadas que las basadas en un guión. Las razones son evidentes aunque quizá aquí está el quiz de la cuestión; en la novela, el público parece exigir un nivel de "realismo" mayor que en las películas. 
hace que la profesión (en este caso paleontólogo y paleobotánica) pierda su sentido. Cuando descubren lo que esconde el parque, la nieta de Hammond le pregunta a Alan Grant, "¿quévan a hacer usted y Eli ahora que no tienen que excavar buesos de dinosaurios?" a lo que responde Grant, "no sé, supongo que también tenemos que evolucionar". Dado que ya podemos ver, tocar y oír a los dinosaurios (los hechos), la Historia (natural en este caso) está ya explicada cumpliendo así el ideal positivista: contar con TODOS los datos en vivo y en directo. Timeline representa el lado contrario, quizá incluso más interesante. En este filme un grupo de arqueólogos medievales tiene que viajar al pasado para rescatar a uno de ellos que ya ha viajado previamente, por lo que pueden ser testigos de la Historia que ellos mismos están desenterrando en el presente. En una escena, dos de los protagonistas se paran a contemplar una de las casas que habían estado excavando y charlan emocionados sobre las hipótesis que manejaban y que ahora se veían contrastadas.

Lo que recibe el público en las películas es que si vivieran los dinosaurios no necesitaríamos excavarlos y que si pudiéramos trasladarnos a la Edad Media tendríamos resueltos todos los problemas históricos. Sin embargo, las películas no transmiten esta idea del "problema histórico"; de que un dinosaurio hoy, en el supuesto caso de que pudiéramos clonarlos, no tendría absolutamente nada que ver con el dinosaurio de hace 70 millones de años del mismo modo que el simple hecho de ver una casa en la Francia del siglo XIV no explicaría per se la sociedad de la Francia del siglo XIV, por muchos datos concretos que nos pudiera proporcionar. La Arqueología, como ciencia, como búsqueda de la "verdad histórica" queda así destruida: "La arqueología busca el hecho, no la verdad. Si es la verdad lo que les interesa, el doctor Tilly da Filosofía en la clase del fondo" (Indiana Jones y la Última Cruzada).

Algunas notables excepciones de esta Arqueología del "search and retrieve" podrían ser $A$ month in the country o The Body. En la primera, la Arqueología responde a un criterio más comercial y privado; el arqueólogo, James Moon, es contratado para encontrar los restos de un antepasado de una noble del pueblo, pero lo que realmente hace James es excavar una basílica sajona del siglo VI d.C ${ }^{22}$. Este carácter más comercial de la Arqueología es un aspecto destacado de películas como Jurassic Park o Westworld. En la primera, el conocimiento paleontológico sirve para que un amable capitalista, Hammond, pueda construir el parque de sus sueños, mientras que su abogado sólo puede ver las ganancias que puede reportar. En la segunda, el conocimiento arqueológico sirve, igualmente, para construir un parque en el que se recrea, mediante robots y escenarios, diferentes mundos (una villa romana, un castillo o el lejano oeste) que sirven para el ocio de los clientes.

22 El personaje de James Moon es una visión bastante aproximada de la pugna actual entre los intereses de la Arqueología en el mercado (normalmente liberar el suelo; en este caso, encontrar un "objeto" personal) y la academia (investigar con lo que se puede sacar durante la excavación de urgencia). 


\title{
2.2. La metodología de la ¿ciencia? Arqueológica
}

\begin{abstract}
Sir Joseph: No hemos venido a Egipto en busca de medallas. Se aprende más de los pequeños trozos de cerámica que de los descubrimientos sensacionalistas. Nuestra tarea es mejorar los conocimientos acerca del pasado y no satisfacer nuestra curiosidad. (La Momia, 1932)

Leo: Le daremos el 20\% [del tesoro] si la información lo justifica. Queremos que nos diga todo lo que sepa de un azteca que vino aqui en el siglo XVI, ¿conoce la historia?

(El templo del oro, 1986)
\end{abstract}

Si pudiéramos hacer una división cuantitativa del trabajo del arqueólogo actual descubriríamos que más del $80 \%$ de su tiempo se dedica a cuestiones administrativas (redacción de informes, búsqueda de financiación, política...) y a trabajos de laboratorio (lavado y catalogación, análisis de materiales, realización de inventarios) y lo que es tiempo de excavación se reduce, a lo sumo, a un par de meses al año. Todo este gran trabajo administrativo y burocrático es absolutamente invisible en las películas. En la Arqueología del "search and retrieve" el arqueólogo pasa la mayor parte de su tiempo en "labores de campo" como matar nazis (Indiana Jones: en busca del Arca perdida), luchando contra ejércitos resucitados (La Momia 2: el regreso; La Momia 3: la tumba del emperador Dragón) o contra las fuerzas del mal (Doc Savage: man of bronze).

El trabajo ante y post excavación tiene, por tanto, un pobrísimo reflejo en las películas. Esto es lo que recibe el espectador; la Arqueología no tiene un método definido, no establece hipótesis, no resuelve incógnitas y no hace trabajo administrativo. Como muestran los sutiles métodos de Chuck Norris en El templo del Oro para localizar el tesoro ${ }^{23}$, la Arqueología no es una ciencia ni una profesión por la que merezca la pena ser remunerado. Un par de escenas, sin embargo, rompen esta regla general. En una ejemplar demostración de buen quehacer arqueológico, La Momia (1932) muestra un momento en el que sir Joseph está analizando unas cerámicas y anotando sus características en una libreta mientras su joven aprendiz se muestra visiblemente aburrido; sir Joseph le explica: "Ser metódico es vital en Arqueología. Todos los descubrimientos deben registrarse al momento".

El lugar de trabajo del arqueólogo es, sin duda, el campo. Los laboratorios, las clases, los despachos... son entornos extraños y aburridos para los arqueólogos, cuya actividad se desarrolla en lugares exóticos y lejanos. Actualmente, al igual que ocurre en carreras como Filosofía o Historia, una

23 Concretamente la escena se desarrolla en una habitación de motel. Chuck Norris y su compañero están intentando decidir dónde puede estar el supuesto tesoro, ya que ni siquiera saben si existe, dentro del marco geográfico de toda América Central. La mujer que los ha embarcado en la aventura se levanta de la cama como poseída y se dirige al mapa y clava un puñal "mágico" en el mapa; "San Miguel!" gritan ambos, y allí se dirigen para su búsqueda. 
de los salidas laborales más normales es la docencia. Sin embargo, en las clases, el arqueólogo de las películas se siente un ser alienado, arrancado de su hábitat natural que es la aventura; "Here lies one of the fascinating ironies of the depiction of archaeologists in film: the reel archaeologist (as professor in the classroom) attempts to desmitify archaeological work, while succumbing to its atavistic pleasures and promises in real life" 24 . En una escena de Indiana Jones y la Última Cruzada el profesor Jones se ve acosado por decenas de alumnos que, ante sus habituales salidas de campo, apenas han podido acudir a sus tutorías. Jones acaba huyendo por la ventana aceptando minutos después la oferta de buscar el mismísimo santo Grial ${ }^{25}$.

Son varias las películas en las que podemos observar algún tipo de excavación arqueológica (Jack Hunter y el tesoro perdido de Ugarit, La Momia 3. La tumba del emperador Dragón; Stargate; Indiana Jones: en busca del Arca perdida; Manbattan Baby, El exorcista...) y generalmente se representa de forma similar; excavaciones masivas de cientos de personas sin ningún orden establecido ${ }^{26}$, simplemente quitando tierra hasta que en algún momento se escucha un "ibe encontrado algo!" y todo el mundo corre para observar lo que se ha localizado. Normalmente como el objetivo de este tipo de excavaciones es encontrar ese objeto, una vez hecho, la excavación deja de tener sentido, ¿para qué seguir excavando si tenemos lo que queremos? ¿Para qué registrar todas las estructuras y guardar los materiales? ¿Para qué hacer arqueología?

La Arqueología, de nuevo, deja de ser una ciencia y sólo se expresa como un compendio de datos que sólo interesan a una minoría (como el caso del personaje del médico alemán en Muerte en el Nilo, que aburre a todos con su sabiduría de la cultura egipcia o el personaje de Benjamin Gates en las dos partes de La Búsqueda). Las verdaderas ciencias son otras. En la película Timeline un componente del equipo de excavación no sólo es paleógrafo y sabe distinguir grafías de hace 600 años, sino que también es el que realiza la prueba del Carbono 14 y también es experto en jfísica cuántica! Por supuesto es el que se encarga de la parte "científica" de la excavación, "confirmando" lo que los arqueólogos, no científicos, "hipotetizan"27.

24 El uso como adjetivo del sustantivo "reel" (carrete) es utilizado por el autor conscientemente para contraponerlo con "real". HOWARD DAY, D. (1997). A treasure bard to attain. Images of Archaeology in popular film, with a filmography. Londres: The scarecrow press. pp. 13-14.

25 Es muy interesante la evolución que siguen las enseñanzas del doctor Jones desde los inquietos años 80, en los que afirmaba que "El $70 \%$ de la Arqueología se hace en la biblioteca, investigando, leyendo" mientras que en los posmodernos primeros años del siglo XXI le recomienda a un alumno que "si quieres ser un buen arqueólogo, tienes que salir de la biblioteca".

26 HALL, M. (2004). Romancing the stones: archaeology in popular cinema. European Journal of Archaeology, 7(2), 159-176.

27 El mito del Carbono 14 como arma que resuelve todas las cuestiones cronológicas es algo muy asumido por el público. En esta misma película, Timeline, cuando descubren el manuscrito del profesor que ha viajado en el tiempo le preguntan al experto si ha realizado 
Si ya la Arqueología real es "destructiva" la Arqueología filmada es catastrófica. Más allá del ejemplo de Albert Littman tirando las cerámicas al suelo, otro similar es la espantosa escena de Lara Croft: Tomb Raider en la que observamos a medio centenar de vietnamitas tirando con cuerdas de una estatua gigante del templo de Angkor hasta que se cae, logrando así una entrada. La filosofía maquiavélica del "fin justifica los medios" es una constante y, ya sea para proteger al mundo de los nazis, salvarnos de una catástrofe natural o perseguir un sueño personal, todo está permitido.

De nuevo, The Body es un gran ejemplo de buena metodología arqueológica. La excavación realizada en Jerusalén podría ser una intervención actual en la que se observan estaciones totales, material de excavación, contenedores de materiales, fichas, etc. Cuando entran en la tumba (supuestamente de Jesús de Nazaret) encuentran una moneda en el suelo que meten en una bolsa de plástico y que luego servirá para datar el yacimiento junto con la termoluminiscencia (asombrosamente bien explicada y aplicada) y el Carbono 14 que, como en la realidad, da un margen de error más o menos amplio. Incluso la arqueóloga tiene que elaborar un informe de la excavación para la administración israeli ${ }^{28}$. Todo un ejemplo de cine arqueológico bien hecho.

\subsection{Las sociedades del pasado: presentismo, exotismo, imperialismo}

Imhotep: A los egipcios no se nos permite desenterrar a nuestros muertos, sólo a los museos extranjeros

(La Momia, 1932)

Indiana Jones: Es lícito apoderarse de sus contenidos [de una tumba], no confundáis eso con robar, en todo caso es retirar el contenido del túmulo

(Indiana Jones: en busca del arca perdida, 1981)

Para la Arqueología del cine rara vez es el conocimiento de las sociedades del pasado lo que motiva la búsqueda. En realidad, todo, incluido el Pasado (con mayúsculas), se analiza desde un punto de vista actual, presentista. Las sociedades y los objetos del pasado se contemplan desde el presente y es en el presente en el que cobran sentido; irónicamente, el pasado está hecho para el presente.

En las numerosas aventuras que corren los arqueólogos entran en

bien la prueba del Carbono 14 sobre el papel. Él responde que por supuesto que lo ha hecho y que la ha repetido jtres veces! Todo esto en el mismo campo de trabajo. Este tipo de inexactitudes conducen a que el público reciba una imagen muy distorsionada de la Arqueología, que contrasta con la Arqueología real.

28 Este filme destaca igualmente por la imagen que ofrece de la actual arqueología israelí en la que ciertamente ocurren los problemas descritos por la película, como la oposición de los judíos ortodoxos a excavar cementerios judíos TRIGGER, B. (2009). A bistory of Archeological Thought. Cambridge: Cambridge University Press. pp. 503-504. 
contacto con lugares, edificios, trampas... que se fabricaron para el momento actual en el que el arqueólogo trata de recuperar los objetos. Se entiende siempre que la sociedad del pasado hizo todo eso no por una necesidad de aquel entonces, si no para el futuro, (el presente fílmico) como proteger el tesoro mediante distintos artilugios (algunas veces exageradamente sofisticados, como en Lara Croft: Tomb Raider), poner pistas para llegar hasta ellos (La Búsqueda: el tesoro nacional) o, directamente, hacer mapas para su localización (El templo del oro). Ya no es ni siquiera que el objeto de la Arqueología sea el conocimiento de las sociedades del pasado, sino que el propio pasado está al servicio del arqueólogo y sus aventuras.

Con ello lo que se transmite es una capacidad de apropiación del pasado para utilizarlo en el presente. Una apropiación que en muchas ocasiones supone una total reinterpretación del mismo pasado en función de los intereses concretos del arqueólogo (o el enemigo del arqueólogo) de turno. Las consecuencias son dos: por un lado reforzar la idea de que la Arqueología no es nada más allá del objeto; su objetivo no es estudiar el pasado, sino hacerse con él y utilizarlo. Por otro se consigue justificar lo injustificable dentro de una narrativa fílmica; toda acción es totalmente lícita para que el arqueólogo se apropie de ese pasado para su motivación personal en el presente. Una lógica del "todo vale" (anything goes) muy adecuada al capitalismo occidental que justifica la apropiación del pasado en función del presente económico ${ }^{29}$.

Aunque la Arqueología se está globalizando a pasos agigantados, lo normal es que los arqueólogos desarrollen su trabajo en un ámbito geográfico muy reducido, usualmente regional. En las películas suele ocurrir exactamente lo contrario; rara vez la Arqueología trabaja en el propio país, ni siquiera en Occidente (con excepciones como $A$ month in the country, Timeline o las dos películas de La Búsqueda). Lo normal es tener que ir a buscar el tesoro o el objeto a sitios exóticos y lejanos asociando así la idea de que los tesoros están lejos y en zonas desconocidas o misteriosas a nuestra realidad cercana. Los destinos pueden ser muy variados: Vietnam (Lara Croft: Tomb Raider), Brasil (The Relic), China (La máscara de Fu Manchu), Centroamérica (El templo del oro) o el icono de la Arqueología para el público, Egipto ${ }^{30}$.

La Arqueología desde el punto de vista presentista actúa normalmente como un instrumento puramente imperialista; el arqueólogo (occidental) viaja a estos destinos exóticos para hacerse con un objeto o tesoro de alguna cultura pasada que vivía en esos lugares y que normalmente suele conllevar un evidente expolio, ya sea porque se quiere efectivamente robar (Lara

29 Con cierta distancia, es lo mismo que ocurre con el problema ecológico; la naturaleza y sus recursos están hecha para el hombre (y la empresa) del presente sin tener en cuenta ni el pasado ni el futuro.

30 HALL, M. (2004). Romancing the stones: archaeology in popular cinema. European Journal of Archaeology, 7(2), 159-176. 
Croft: Tomb Raider) o hay que tomarlo por "éticas" razones (Jack Hunter y el tesoro perdido de Ugarit); "what this [mummy] films retain is a depiction of archaeology as a colonial imposition by which cultural inheritance is appropriated" 31 . El alegato de Indiana Jones, "es licito apoderarse de sus contenidos" no puede ser más definitorio.

El peor papel se lo llevan los nativos de esos países lejanos, retratados con estereotipos algunas veces rayando lo racista, y que suelen quedar relegados a un papel servil (usualmente son los que cogen el pico mientras el arqueólogo se dedica a labores menos físicas, como en Lara Croft: Tomb Raider o La Momia 3: la tumba del emperador Dragón) y dependiente del occidental que viene a robar sus posesiones. La descripción de Mark Hall es, en este sentido, muy ajustada; "Often, but not exclusively, such forays are set in the 1920s or 1930s and so often display hundreds of Egyptians as the labouring force under foreing, imperial archaological control" 32 . Dos escenas nos pueden servir para ilustrar este tipo de imperialismo occidentalista. En la vergonzosamente racista La máscara de Fu Manchu observamos como el equipo de arqueólogos logra entrar en la tumba de Gengis Khan seguidos de sus sirvientes asiáticos, que, al contemplar la tumba, asumen su papel de "bárbaros" y se postran ante ella, lo que hace que los arqueólogos se enfaden y tengan que echarlos a patadas y disparos de pistola. En Jack Hunter y el tesoro perdido de Ugarit vemos una excavación en Siria, que, llevada a cabo por los nativos, tiene que ser vigilada por Albert Littman (el arqueólogo) y sus hombres a punta de metralleta. Cuando le comunican que le han retirado el permiso de excavación, Albert se da cuenta de que hay un traidor entre los excavadores, por lo que decide encerrarlos a todos en la excavación y hacerlos explotar con una bomba. Como ya se ha dicho, todo vale y lo preocupante es que hagan creer al público que esa lógica fílmica podría ser similar a la realidad, esto es, que en países lejanos y extraños se puede robar los tesoros a punta de pistola.

\section{EL ARQUEÓlOGO: UNA PROFESIÓN DISTORSIONADA}

\subsection{El perfil del arqueólogo de cine}

Tom Baxter: Soy Tom Baxter, explorador, aventurero...

Estoy realizando un proyecto arqueológico

(La Rosa Púrpura del Cairo, 1985)

Wilson: Ahora saqueo tumbas en nombre de la conservación

(La Momia 3: la tumba del emperador Dragón, 2008)

Un perfil estándar del arqueólogo-tipo de las películas podría ser: varón de mediana edad (30-45 años), soltero, heterosexual, europeo o usamericano, de formación variada (desde doctores en Arqueología como

31 Ibid. p. 161.

32 Ibid. p. 162. 
Indiana Jones hasta simples aficionados sin carrera, como Max/Chuck Norris de El templo del oro) y con especiales habilidades para el combate cuerpo a cuerpo y manejo de distintas armas. Por supuesto, esto nada tiene que ver con la realidad y responde más a cuestiones de guión, como la necesidad de poseer ciertas habilidades que permitan escenas de acción y no romper así con el ritmo de la película. Sin embargo, la visión que el cine ofrece de los arqueólogos al público determina en gran parte su posición en el sistema de estratificación social. Veamos esto con más detalle.

Si la Arqueología busca y encuentra el arqueólogo directamente saquea. Profesionalmente es un "buscador de tesoros" o "saqueador" y en muchas películas se refieren a él o ella con esos mismos términos (Lara Croft: Tomb Raider; La buisqueda 2: el diario secreto; Tomb Raider 2: la cuna de la vida; La Momia Nacional; La Momia 3: la tumba del emperador Dragón...). En pocas ocasiones el arqueólogo es realmente arqueólogo de profesión, con la, otra vez, notable excepción de The Body.

Este tipo de cuestiones transmiten al público una idea muy errónea de lo que realmente hace el arqueólogo y, con ello, lo que se consigue es que el público realmente no sepa lo que hacen los arqueólogos. Si a través de las películas se planteara la pregunta ¿de qué viven los arqueólogos? La respuesta mayoritaria es que viven de los tesoros que expolian y venden como mercenarios (Jack Huntery el tesoro perdido de Ugarit; Indiana Jones: en busca del arca perdida) de la fama (La búsqueda 2: el diario secreto), de su propia herencia (Lara Croft: Tomb Raider) o, directamente, están en el paro (Stargate). En las películas, por tanto, los arqueólogos pueden dedicarse a su afición por buscar tesoros ya que no hay una preocupación por lograr un trabajo; el arqueólogo no tiene un puesto en la sociedad por el que tenga que ser remunerado.

En la realidad la situación laboral del arqueólogo dista mucho del mundo fílmico. Si bien la sociedad, al desconocer a qué se dedica exactamente un arqueólogo, no le asigna una función social clara, el capitalismo le ha dado un papel más definido a la Arqueología; la de liberar el suelo para hacerlo urbanizable. Desde 1985 en nuestro país es obligatorio que haya un arqueólogo controlando el impacto de las obras de construcción sobre el patrimonio y, en su caso, realizar una excavación. Sin embargo, el curioso desarrollo de, por un lado, esta misma legislación y, por otro, del sistema educativo arqueológico ${ }^{33}$ ha provocado que ni siquiera haga falta tener una formación de arqueólogo para ejercer como tal, dándose casos de arqueólogos suscritos a un convenio laboral de jardinero o minero. Si la sociedad, la administración y las empresas no entienden que para hacer Arqueología se tiene que ser arqueólogo, esta distorsión en la imagen de la Arqueología tendrá repercusión en el mundo laboral.

Esta problemática hasta hace poco sólo preocupaba a una minoría,

33 QUEROL, M. Á. (2001). La formación y la profesión del arqueólogo. La formación arqueológica universitaria: un futuro por el que luchar. PHBoletin(37), 32-34. 
mientras la situación económica se ha desarrollado a golpe de liberalización, especulación y descontrol, mientras hubiera algo de trabajo para la mayoría, el problema no era especialmente grave. Esto, sin embargo, ha cambiado en la actualidad. La crisis económica que ha golpeado con especial énfasis a las empresas del ladrillo ha tenido como consecuencia indirecta una depresión profunda en las empresas arqueológicas y una precarización enorme en los puestos arqueológicos ${ }^{34}$. El cine, al ocultar este tipo de realidades, hace que el público ni las conozca ni las tenga en consideración.

\subsection{La imagen de las arqueólogas}

Liz: nada de lios, ni ataduras. Vender reliquias al mejor postor.

Continuar con la próxima aventura. Ese es Jack Hunter (Jack. Hunter y el tesoro perdido de Ugarit, 2008)

Fu Manchu: soy el hombre más desafortunado. No tengo ningún bijo que me siga. Asi que, vergonzosamente, os pido que recibáis un mensaje de mi fea e insignificante hija.

(La máscara de Fu Manchu, 1932)

Si hemos definido al profesional como un arqueólogo no ha sido inconscientemente. La presencia femenina en las películas de Arqueología no sólo es mínima, sino también secundaria y dependiente. De todas las películas analizadas, en doce hay una arqueóloga o derivadas que ejerzan un papel protagonista en la relación con el objeto arqueológico, de las cuales 2 son de la saga La búsqueda, otras dos de Tomb Raider y tres de la saga La Momia. De éstas, sólo en dos podemos afirmar que la mujer tiene un papel protagonista e independiente de la figura de un hombre: Jurassic Park y The Body. En las demás (Jack Hunter y el tesoro perdido de Ugarit; La búsqueda o Timeline;), la mujer actúa muchas veces más como apéndice o personaje secundario del verdadero arqueólogo más que como una profesional.

La excepción la marca, nuevamente, The Body, donde la arqueóloga, Sharon Golban, es retratada como una auténtica profesional. Sin embargo esta no es la imagen común de la mujer en el cine de Arqueología. Dos son los grandes paradigmas; por un lado, Lara Croft sería el equivalente femenino de Indiana Jones. Si Jones representa la masculinidad, el espíritu de aventura y la obsesión por el objeto que caracterizaría a los arqueólogos, Lara Croft representa la sensualidad rayando en lo pornográfico, la falsa independencia femenina (dependiente, irónicamente, de su sensualidad asignada por un paradigma masculino) y la continua autojustificación de su autoridad frente a los hombres.

Por otro lado nos encontramos con la típica "mujer-florero" que sólo

34 PARGA-DANS (2010). Commercial archaeology in Spain: its growth, development, and the impact of the global economic crisis. En N. SCHLANGER \& K. AITCHISON (Eds.), Archaeology and the global economic crisis. Multiple impacts, possible solutions (pp. 45-54). Tervuren: Culture Lab Editions. 
es una representación deformada del ideal machista de mujer. En primer lugar, no es arqueóloga ni se ve motivada por la búsqueda del objeto, sólo la inspiración masculina hace que tome parte en la acción. Aunque, por supuesto, el papel de la mujer ha evolucionado desde los años 40, no ha hecho sino modificar ligeramente sus parámetros. El personaje de Ivy en las películas modernas de La Momia no es sino la modificación acorde a lo "políticamente correcto" de hoy como podría ser, en su momento, el papel de Helen Grosvenor de la película La Momia (1932) o el de Sheila Barton en La Máscara de Fu Manchu.

\title{
3. CONCLUSIONES
}

\author{
Los filósofos no ban becho más que interpretar \\ de diversos modos el mundo, \\ pero de lo que se trata es de transformarlo \\ $(\text { Karl Marx })^{35}$
}

A lo largo del presente trabajo se han puesto de relieve algunas de las características principales de la imagen que muestra el cine "de masas" sobre la Arqueología, el arqueólogo y la arqueóloga. Se trata, como hemos visto, de una imagen tremendamente estereotipada y basada en conceptos propios de hace 150 años, cuando la Arqueología estaba naciendo como ciencia al servicio de los incipientes nacionalismos centroeuropeos y nórdicos ${ }^{36}$. Esta imagen responde tanto a cuestiones históricas como a cuestiones puramente económicas. El cine es una poderosa empresa basada, no tanto en la distribución de cultura, sino en la maximización de beneficios. Una empresa cuya clientela es muy heterogénea, por lo que tiene que ofrecer productos, muy variados, pero sometidos a ciertas reglas de entretenimiento, guión, producción, etc. ${ }^{37}$. Con esto se quiere resaltar que muchos de los "defectos" que detectamos en las películas no responden tanto a una falta de comprensión de la Arqueología ${ }^{38}$, que también, sino de las características de las productoras; en palabras de Theodor Adorno:

"El cine se ve remitido, a través del volumen de los costes de inversión requeridos, a algo análogo al planteamiento administrativo público; sin duda alguna, en él se delinea estremecedoramente la contradicción entre

35 MARX, K. (1988). Antología. Barcelona: Editorial Península. p. 610.

36 TRIGGER, B. (2009). A history of Archeological Thought. Cambridge: Cambridge University Press. pp. 121 y ss. Resulta curioso que sea también en estos momentos cuando nació la novela histórica, como precedente inmediato de las películas históricas y, por extensión, las arqueológicas, HERNÁNDEZ DESCALZO, P. J. (1997). Luces, cámara, ¡Acción!: Arqueología, toma 1. Complutum(8), 311-334.

37 HALL, M. (2004). Romancing the stones: archaeology in popular cinema. European Journal of Archaeology, 7(2), 159-176.

38 HOWARD DAY, D. (1997). A treasure hard to attain. Images of Archaeology in popular film, with a filmography. Londres: The scarecrow press. 
lo perentoriamente calculatorio y la verdad de la cosa, y la puerilidad de las películas no dimana tanto de una insuficiencia individual cuanto de esta contradicción; su principio es la previsión planeadora, destemplada, que incluye en su cálculo al espectador"339.

El cine, pues, no sólo utiliza y aprovecha los tópicos generados en el público ${ }^{40}$, sino que los realimenta en una especie de círculo sin fin. Nos guste o no, la imagen de la Arqueología recibida por el público es, a grandes rasgos, la que hemos descrito en el trabajo y es la que mayoritariamente reciben de esta ciencia (un estudio publicado por Russell en 2002 sugería que el $98 \%$ de los británicos no tenían más contacto con la Arqueología que a través del cine ${ }^{41}$ ) y es la idea que conservarán en el desarrollo de su vida social, política y económica.

También, como hemos sugerido, en la vida real, fuera de las películas, la Arqueología y los arqueólogos se ven sometidos a fuertes constricciones en su trabajo. Un trabajo que se ve afectado por todo los problemas actuales del mundo laboral; precariedad, temporalidad, salarios bajos, competencia extrema... y que, además, se ven agravadas por las características concretas del papel asignado por el sistema económico a la Arqueología en el mundo social que es liberar el suelo de "obstáculos" para poder construir infraestructuras. Y, también, un trabajo que, al haberse transformado tan radicalmente en los últimos 20 años aún no tiene definida una formación concreta (los arqueólogos... ¿¿somos sólo historiadores? ¿Somos sólo administradores de patrimonio? ¿Somos sólo gestores de información? ¿Somos todo lo anterior? Y, por tanto, ¿cuál es la formación necesaria?). Situación que, además, se ha visto inmersa en el caótico (y nada inocente ${ }^{42}$ ) cambio de planes de estudio que es el Plan Bolonia.

Todo este planteamiento tiene un problema de base y es que, para decirlo en pocas palabras: la sociedad no sabe qué hace exactamente un arqueólogo ni para qué sirve realmente la Arqueología. Un arqueólogo o arqueóloga no sólo sabe estudiar el pasado histórico a través de los restos materiales (la visión puramente academicista), sino que también es un gestor de información, un recuperador del patrimonio histórico, un actor social de primer orden en los proyectos urbanísticos y de desarrollo rural, etc... Sin embargo, todos estos rasgos y potencialidades de la Arqueología pasan desapercibidas para el público mayoritario, ocultos detrás del "fedora" de Indiana Jones.

39 ADORNO, T. W. (1971). Cultura y administración. En T. W. ADORNO \& M. HORKHEIMER (Eds.), Sociologica (pp. 69-97). Madrid: Taurus.

40 HERNÁNDEZ DESCALZO, P. J. (1997). Luces, cámara, ¡Acción!: Arqueología, toma 1. Complutum(8), 311-334.

41 Citado en HALL, M. (2004). Romancing the stones: archaeology in popular cinema. European Journal of Archaeology, 7(2), 159-176.

42 RUIZ ZAPATERO, G. (2009). ¿Qué arqueología enseñar en la universidad del siglo XXI? Complutum, 20(2), 225-254. 
¿Quiere eso decir que las películas son las culpables de la situación de la Arqueología, los arqueólogos y las arqueólogas? Ni mucho menos. Sin embargo, los medios de comunicación, sobre todo los de masas, y como empresas que son, no hacen sino reflejar una ideología que (hasta que se demuestre lo contrario), es la ideología de la "clase dominante"43, es decir, de aquellos que se lucran con sus beneficios. Esta ideología, en la que el ser humano se ve imbuido a lo largo de su desarrollo, determina en gran parte la estructuración de su mundo social ${ }^{44}$, dentro del cual podemos incluir (¿por qué no?) la Arqueología. En otras palabras; si la sociedad no tiene una necesidad de la Arqueología es porque lo que conoce sobre ella no da a entender sus potencialidades sociales. En términos capitalistas, si no se conoce la oferta, jamás habrá una demanda y el statu quo actual tenderá a permanecer y los arqueólogos y arqueólogas no podremos empoderarnos para combatir esta situación.

Esto nos deja a los profesionales arqueólogos en la situación de sujeto de la solución; es decir, si detectamos, entendemos y compartimos estos problemas que hemos anunciado a lo largo del trabajo, entonces queda claro que somos nosotros los que tenemos que resolver este problema de la distorsión entre las imágenes. El problema está planteado, pero, ¿cómo resolverlo?

En uno de sus recientes artículos, el político Julio Anguita expresaba la idea de que una "lógica sólo se combate con otra distinta, confrontada, alternativa y organizada" 45 y así surgen algunas propuestas interesantes como el de una arqueología "militante" ${ }^{46}$ y comprometida. Una Arqueología que comience por la crítica exhaustiva de todos los componentes en los que se ve envuelto el arqueólogo, estableciendo así la base de la transformación. Como apuntaba Horkheimer, "la teoría que tiende a la transformación de la totalidad social tiene, por lo pronto, como consecuencia, que la lucha con la que está relacionada se agudice" ${ }^{\prime 7}$. De aquí la importancia de estudiar el cine, por muy poco "científico" que pueda parecer, ya que de lo que se trata es de localizar las contradicciones inherentes y agudizarlas, exponerlas de manera que sean visibles a todos; y a todos sea posible encontrar una solución. En

43 MARX, K. (1988). Antología. Barcelona: Editorial Península. p. 131 y ss.

44 GRAMSCI, A. (1976). Introducción a la filosofía de la praxis. Barcelona: Ediciones Península, BOURDIEU, P. (1997). Razones prácticas. Sobre la teoría de la acción. Barcelona: Anagrama.

45 ANGUITA, J. (2010). Una lógica sin oponentes. http://arepublica.es/firmas/blogs/ index.php/julioanguita/2010/07/15/una-logica-sin-oponente [consultado el 24/02/2011] 46 FALQUINA APARICIO, Á., MARÍN SUÁREZ, C., ROLLAND CALVO, J. y TIERRA DE NADIE, G. A. (2006). Arqueología y práctica política. Reflexión y acción en un mundo cambiante. Arqueoweb: revista sobre Arqueología en Internet, 8(1).

47 HORKHEIMER, M. (2003 [publicado en 1937]). Teoría tradicional y teoría crítica. En M. HORKHEIMER (Ed.), Teoría crítica (pp. 223-271). Madrid-Buenos Aires: Amorrortu Editores. 
palabras de Ruiz Zapatero y Fernández Martínez: "pensamos que ocuparse de estas "fronteras menores" [el cine] de nuestra disciplina no es rendirse a una moda pasajera, sino apostar por una mayor efectividad para lograr el gran reto del futuro: comunicar a la sociedad el verdadero valor de la arqueología y del patrimonio arqueológico"48.

El siguiente paso es el de la praxis social, esto es, poner en práctica los análisis hechos a partir de la teoría mediante los diversos instrumentos de los que la Arqueología se puede dotar para la actuación social. Si el objetivo del arqueólogo o arqueóloga "militante" es la transformación, y no únicamente la interpretación, los instrumentos serán todos aquellos que se hayan demostrado transformadores de la realidad social. Sólo mediante la práctica arqueológica social podremos hacer de la Arqueología una ciencia verdaderamente social.

En su libro sobre la Historia en el cine, Rosenstone comenta cómo un historiador mandó una carta a un productor de Hollywood exigiéndole mayor rigurosidad a las películas mediante la presencia de un asesor en los rodajes ${ }^{49}$. Sin embargo, esto es empezar la casa por el tejado. La lógica debería ser la contraria; primero establecer esa base crítica necesaria para la transformación y transferir el conocimiento (que no transmitirlo) ${ }^{50}$ a la sociedad mediante distintos recursos y acciones para que sea la sociedad quién entienda lo que hacemos para, precisamente, exigírnoslo. No es cuestión de cambiar el cine-reflejo de la sociedad sino cambiar la sociedad que el cine quiere reflejar.

48 RUIZ ZAPATERO, G., y MANUEL FERNÁNDEZ, V. (1997). Arqueología: Imagen y proyección social. Complutum(8), 263-264.

49 ROSENSTONE, R. A. (1997). El pasado en imágenes. El desafío del cine a nuestra idea de la Historia. Barcelona: Ariel.

50 CASTRO MARTÍNEZ, E., FERNÁNDEZ DE LUCIO, I., y PÉREZ MARÍN, M. (2008). La transferencia de conocimientos desde las humanidades: posibilidades y características. ARBOR Ciencia, Pensamiento y Cultura(732), 616-636. 